\title{
Skrining Aktivitas Anti Tuberkulosis Tumbuhan Obat Riset Tumbuhan Obat dan Jamu 2012
}

\author{
(Anti Tuberculosis Activity Screening Riset Tumbuhan Obat dan Jamu 2012 Medicinal Plants)
}

Penulis

Afiliasi

\section{Galuh Ratnawati ${ }^{*}$ Nita Supriyati, Tri Widayat}

Balai Besar Penelitian dan Pengembangan Tanaman Obat dan Obat Tradisional, Badan Litbang Kesehatan, Kementerian Kesehatan RI. Jl Raya Lawu No. 11 Tawangmangu, Karanganyar, Jawa Tengah, Indonesia 57792

\section{Kata kunci \\ O L Modified Agar \\ - MTB H37Rv \\ $\Rightarrow$ Tuberkulosis \\ Keyword \\ - L Modified Agar \\ - MTB H37Rv \\ $\rightarrow$ Tuberculosis}

Diterima 1 Februari 2019

Direvisi 24 Mei 2019

Disetujui 3 Juni 2019

*Penulis Koresponding Galuh Ratnawati email: galuhratnagaluh@gmail.com

\section{ABSTRAK}

Tuberkulosis merupakan salah satu penyakit menular penting di dunia dan ditetapkan sebagai global emergency oleh World Health Organization (WHO). Indonesia menjadi salah satu negara dengan insidensi tuberkulosis tertinggi di dunia, yaitu peringkat kedua setelah India pada tahun 2015 dengan jumlah penderita mencapai 1.020.000 jiwa. Penelitian Ristoja 2012 telah menghasilkan data yang besar terkait tanaman obat dan manfaatnya untuk beberapa gejala penyakit. Data hasil Ristoja memuat daftar tumbuhan dan khasiatnya, salah satunya adalah untuk pengobatan tuberkulosis. Penelitian ini bertujuan untuk mendapatkan tumbuhan obat yang memiliki potensi anti tuberkulosis berdasarkan data Penelitian Ristoja 2012. Penelitian menggunakan 29 sampel tumbuhan tunggal dan 15 ramuan yang dari data Ristoja 2012 merupakan tumbuhan untuk TBC berdasarkan informasi penyehat tradisonal. Uji kepekaan dilakukan menggunakan metode proporsi agar pada media $U$ Modified Agar. Sampel tumbuhan yang telah berbentuk simplisia diserbuk selanjutnya dibuat dalam bentuk infusa dan ekstrak air. Selanjutnya infusa dan ekstrak air diujikan menggunakan kultur bakteri MTB H37Rv konsentrasi $10^{6} \mathrm{cfu} / \mathrm{ml}$ pada media LJ Modified Agar selama 3 minggu berdasarkan metode yang digunakan Laboratorium TB FK UGM. Konsentrasi infusa dan ekstrak air yang digunakan adalah $50 \mathrm{mg} / \mathrm{ml}$ dan $25 \mathrm{mg} / \mathrm{ml}$. Hasil menunjukkan pada dosis $50 \mathrm{mg} / \mathrm{ml}$ sebanyak 9 ekstrak tunggal, antara lain Blumea balsamifera, Clausena excavata, Pluchea indica; dan dosis $25 \mathrm{mg} / \mathrm{ml}$ sebanyak 2 ekstrak tunggal yaitu Angiopteris evecta dan Arenga pinnata serta 1 infusa $5 \%$ tanaman tunggal yaitu Caesalpinia sappan L. menghambat pertumbuhan bakteri. Dan pada dosis $50 \mathrm{mg} / \mathrm{ml}$ sebanyak satu infus ramuan dan dosis $25 \mathrm{mg} / \mathrm{ml}$ sebanyak dua ekstrak ramuan.

\section{ABSTRACT}

Tuberculosis is one of the most important infectious diseases in the world and is designated as a global emergency by the World Health Organization (WHO). Indonesia is one of the countries with the highest incidence of tuberculosis in the world, which is ranked second after India in 2015 with the number of sufferers reaching 1,020,000. The 2012 Ristoja study has produced large data on medicinal plants and their benefits for several symptoms of the disease. Ristoja's results data lists plants and their properties, one of which is for the treatment of tuberculosis. This study aims to obtain medicinal plants that have the potential for anti-tuberculosis based on the 2012 Ristoja Research data. The study used 29 samples of single plants and 15 herbs which from Ristoja 2012 data were plants for tuberculosis based on traditional health information. The sensitivity test was carried out using the proportion method in the LJ Modified Agar media. Plant samples in the form of simplicia were then pollinated and made in the form of infusions and extracts of water. Furthermore, infusion and water extract were tested using MTB H37Rv bacterial culture with a concentration of $106 \mathrm{cfu} / \mathrm{ml}$ in LJ Modified Agar media for 3 weeks based on the method used by TB Laboratory of UGM Faculty of Medicine. The concentration of infusion and water extract used was $50 \mathrm{mg} / \mathrm{ml}$ and $25 \mathrm{mg} / \mathrm{ml}$. The results showed that at a dose of $50 \mathrm{mg} / \mathrm{ml}$ as many as 9 single extracts, including Blumea balsamifera, Clausena excavata, Pluchea indica; and the dose of $25 \mathrm{mg} / \mathrm{ml}$ as much as 2 single extracts, namely Angiopteris evecta and Arenga pinnata and $15 \%$ single plant infusion, Caesalpinia sappan L. inhibits bacterial growth. And at a dose of $50 \mathrm{mg} / \mathrm{ml}$ as much as one infusion of ingredients and a dose of $25 \mathrm{mg} / \mathrm{ml}$ as many as two extracts of the herb. 


\section{PENDAHULUAN}

Riset Khusus Eksplorasi Pengetahuan Lokal Etnomedisin dan Tumbuhan Obat Berbasis Komunitas (Ristoja) bertujuan untuk menghasilkan data jenis tumbuhan obat, ramuan obat tradisional yang digunakan serta pengetahuan lokal etnomedisin di seluruh etnis Indonesia. Ristoja merupakan riset badan litbangkes yang dilaksanakan oleh B2P2TOOT Tawangmangu yang telah dilaksanakan dalam 3 tahap yaitu 2012, 2015, dan 2017. Riset ini telah mengidentifikasi ribuan spesies tumbuhan berkhasiat obat yang digunakan hattra dalam pengobatan berbagai indikasi penyakit.

Ristoja tahun 2012 memperoleh 19.738 informasi tumbuhan untuk 10 indikasi penyakit. Tahun 2015 memperoleh 19.871 informasi tumbuhan sedangkan tahun 2017 memperoleh 11.216 informasi tumbuhan yang digunakan dalam pengobatan (Wahyono et al. 2017). Data Ristoja yang telah dihasilkan membutuhkan penelitian lanjutan untuk membuktikan secara ilmiah mengenai keamanan dan manfaatnya untuk indikasi tertentu. Salahsatu indikasi yang termuat dalam data Ristoja 2012 adalah untuk mengobati TBC, setidaknya terdapat 75 informasi tumbuhan yang digunakan hattra untuk mengobati TBC.

Tuberkulosis (TB) sampai dengan saat ini masih merupakan masalah kesehatan masyarakat di dunia maupun di Indonesia (Kemenkes RI, 2015). Penyakit ini disebabkan oleh Mycobacterium tuberculosisbasilus obligat intraseluler dan aerobik yang berkembang biak dalam makrofag. M. tuberculosis menginfeksi paruparu dan dapat menyebar ke manusia lainnya melalui droplet dari tenggorokan orang yang terinfeksi tuberkulosis (Wahyuningrum et al. 2015). Di seluruh dunia tuberkulosis membunuh sekitar tiga juta orang setiap tahunnya (Bongo et al. 2017). Sejak tahun 1992 WHO telah menetapkan tuberkulosis sebagai global emergency (Christanto, 2018). Indonesia menduduki peringkat kedua insidensi TB tertinggi dunia pada tahun 2015 setelah India. Tahun 2016 penderita TB di Indonesia mencapai 1.020.000 jiwa. Indonesia juga menjadi salah satu negara 20 besar insidensi MDR-TB dengan 32.000 kasus (WHO a, 2017). Strategi END-TB memiliki tiga pilar utama. Pilar pertama adalah penanganan dan pencegahan TB yang terintegrasi dan berbasis pasien, pilar kedua sistem pendukung serta kebijakan yang tegas dan berani, pilar ketiga adalah inovasi dan penelitian yang intens (WHO, 2015).
Data Ristoja 2012 menjadi peluang untuk menemukan kandidat baru tumbuhan yang potensial untuk pengendalian tuberkulosis. Penelitian ini bertujuan untuk mendapatkan tumbuhan obat dari seluruh sampel yang digunakan yang memiliki potensi anti tuberkulosis.

\section{METODE \\ Penelitian Persiapan sampel}

Sampel dipilih secara purposif berdasarkan data Ristoja 2012. Sampel merupakan tumbuhan yang digunakan oleh hattra sebagai informan untuk mengobati TBC (Tabel 1 dan Tabel 2). Persiapan sampel meliputi kegiatan sortasi, pengeringan dan penyiapan serbuk. Bahan dari maisng-masing bagian tanaman dipotong-potong dan dicuci bersih kemudian dikeringkan, selanjutnya masing-masing potongan diserbuk dengan blender dan diayak dengan ukuran 40 mesh. Serbuk disimpan dalam plastik box kedap air sampai siap digunakan.

\section{Pembuatan infus dan ekstrak sampel tumbuhan}

Masing-masing sampel diesktraksi dengan cara infundasi dengan pelarut akuades. Sebanyak $10 \mathrm{mg}$ sampel dimasukkan dalam panci infundasi bersama 100 $\mathrm{ml}$ akuades dipanaskan selama 15 menit pada suhu $90^{\circ}$. Hasil penyarian dikeringkan di dalam oven hingga air menguap sempurna. Ekstrak yang menempel pada seluruh bagian cawan dikerok, dicampur, ditimbang, dimasukkan botol kaca, dibungkus aluminium foil dan disimpan dalam kulkas. Beberapa sampel menggunakan infus segar langsung karena bentuk ekstrak kering sulit untuk dilarutkan kembali. Data ekstrak tanaman tunggal dan ramuan berdasarkan hasil Ristoja 2012 disajikan dalam Tabel 1 dan 2. Perbandingan tumbuhan yang digunakan dalam setiap ramuan adalah 1:1 pada masing-masing tumbuhan penyusun.

\section{Uji anti tuberkulosis dengan bakteri Mycobacterium tuberculosis H37Rv}

Peremajaan dan perbanyakan bakteri. Tabung steril berisi 2 tetes tween 80 (konsentrasi $0.05 \%$ ) dan 10 butir glassbead, ditimbang, dicatat hasil penimbangan. Stok kultur bakteri H37Rv diambil sebanyak 1 ose, dimasukkan ke dalam tabung berisi 2 tetes tween 80 (konsentrasi0.05\%) dan 10 butir glassbead, timbang, catat hasil penimbangan. Selanjutnya vortex sampai bakteri hancur, diamkan 15 menit. Tambahkan akuades 
sebanyak hasil pengurangan diatas dikalikan $10^{3}(\mathrm{ml})$, modified agar, inkubasi pada $37^{\circ} \mathrm{C}$ selama 4 minggu. vortex kembali sampai homogen, diamkan 15 menit. Diperoleh suspensi bakteri $10^{8} \mathrm{cfu} / \mathrm{ml}$. Ambil $100 \mu \mathrm{l}$ suspensi bakteri, ratakan pada permukaan media LJ

Tabel 1. Data Ekstrak Tanaman Tunggal Skrining Anti Tuberkulosis

\begin{tabular}{|c|c|c|c|}
\hline Kode Ekstrak & Tanaman & Bagian Yang Digunakan & Kegunaan \\
\hline \multirow{3}{*}{ TBR 2} & Leersea hexandra & Daun & TBC \\
\hline & Ceiba pentandra & Daun & \\
\hline & Pistia stratiotes & Herba & \\
\hline \multirow{2}{*}{ TBR 4} & Gynura procumbens & Daun & TBC \\
\hline & Allium sativum & Umbi & \\
\hline \multirow{6}{*}{ TBR 5} & Coix lacryma-jobi & Akar & TBC \\
\hline & Saccharum officinarum & Akar & \\
\hline & Musa x paradisiaca & Akar & \\
\hline & Carica papaya & Akar & \\
\hline & Morinda citrifolia & Akar & \\
\hline & Oryza sativa & Beras & \\
\hline \multirow{2}{*}{ TBR 6} & Blumea balsamifera & Daun & TBC \\
\hline & Clausena excavate & Daun & \\
\hline \multirow{2}{*}{ TBR 7} & Curcuma domestica & Rimpang & TBC \\
\hline & Ketumbar & Biji & \\
\hline \multirow{2}{*}{ TBR 8} & Jatropha curcas & Akar & TBC \\
\hline & Citrus aurantifolia & Air jeruk & \\
\hline \multirow{2}{*}{ TBR 9} & Artemisia vulgaris & Daun & TBC \\
\hline & Curcuma xanthorrhiza & Rimpang & \\
\hline \multirow{3}{*}{ TBR 10} & Vitex trifolia & Pucuk daun & TBC \\
\hline & Loranthus sp & Herba & \\
\hline & Orthosiphon aristatus & Pucuk daun & \\
\hline \multirow{3}{*}{ TBR 11} & Artocarpus heterophyllus Lamk & Buah & TBC \\
\hline & Sesbania grandiflora & Kulit batang & \\
\hline & Lannea coromandelica & Kulit batang & \\
\hline \multirow{2}{*}{ TBR 12} & Tamarindus indica & Buah & TBC \\
\hline & Curcuma heyneana & Rimpang & \\
\hline \multirow{2}{*}{ TBR 13} & Aleurites moluccana & Daun tua & TBC \\
\hline & Cocos nucifera & Sabut & \\
\hline \multirow{2}{*}{ TBR 14} & Curcuma domestica & Rimpang & TBC \\
\hline & Plumeria rubra & Kulit batang & \\
\hline \multirow{2}{*}{ TBR 15} & Blumea lacera & Akar & TBC \\
\hline & Cocos nucifera & Air Kelapa muda & \\
\hline \multirow{3}{*}{ TBR 18} & Cymbopogon nardus & Akar & TBC \\
\hline & Areca catechu & Daging buah & \\
\hline & Jatropha curcas & Kulit batang & \\
\hline \multirow{2}{*}{ TBR 19} & Cassytha filiformis & Batang & TBC \\
\hline & Dracaena angustifolia & Daun & \\
\hline
\end{tabular}


Tabel 2. Data Ekstrak Ramuan Skrining Anti Tuberkulosis

\begin{tabular}{|c|c|c|c|}
\hline Kode Ekstrak & Tanaman & Bagian Yang Digunakan & Kegunaan \\
\hline \multirow{3}{*}{ TBR 2} & Leersea hexandra & Daun & TBC \\
\hline & Ceiba pentandra & Daun & \\
\hline & Pistia stratiotes & Herba & \\
\hline \multirow{2}{*}{ TBR 4} & Gynura procumbens & Daun & TBC \\
\hline & Allium sativum & Umbi & \\
\hline \multirow{6}{*}{ TBR 5} & Coix lacryma-jobi & Akar & TBC \\
\hline & Saccharum officinarum & Akar & \\
\hline & Musa x paradisiaca & Akar & \\
\hline & Carica papaya & Akar & \\
\hline & Morinda citrifolia & Akar & \\
\hline & Oryza sativa & Beras & \\
\hline \multirow{2}{*}{ TBR 6} & Blumea balsamifera & Daun & TBC \\
\hline & Clausena excavate & Daun & \\
\hline \multirow{2}{*}{ TBR 7} & Curcuma domestica & Rimpang & TBC \\
\hline & Ketumbar & Biji & \\
\hline \multirow{2}{*}{ TBR 8} & Jatropha curcas & Akar & TBC \\
\hline & Citrus aurantifolia & Air jeruk & \\
\hline \multirow{2}{*}{ TBR 9} & Artemisia vulgaris & Daun & TBC \\
\hline & Curcuma xanthorrhiza & Rimpang & \\
\hline \multirow{3}{*}{ TBR 10} & Vitex trifolia & Pucuk daun & TBC \\
\hline & Loranthus sp & Herba & \\
\hline & Orthosiphon aristatus & Pucuk daun & \\
\hline \multirow{3}{*}{ TBR 11} & Artocarpus heterophyllus Lamk & Buah & TBC \\
\hline & Sesbania grandiflora & Kulit batang & \\
\hline & Lannea coromandelica & Kulit batang & \\
\hline \multirow{2}{*}{ TBR 12} & Tamarindus indica & Buah & TBC \\
\hline & Curcuma heyneana & Rimpang & \\
\hline \multirow{2}{*}{ TBR 13} & Aleurites moluccana & Daun tua & TBC \\
\hline & Cocos nucifera & Sabut & \\
\hline \multirow{2}{*}{ TBR 14} & Curcuma domestica & Rimpang & TBC \\
\hline & Plumeria rubra & Kulit batang & \\
\hline \multirow{2}{*}{ TBR 15} & Blumea lacera & Akar & TBC \\
\hline & Cocos nucifera & Air Kelapa muda & \\
\hline \multirow{3}{*}{ TBR 18} & Cymbopogon nardus & Akar & TBC \\
\hline & Areca catechu & Daging buah & \\
\hline & Jatropha curcas & Kulit batang & \\
\hline \multirow{2}{*}{ TBR 19} & Cassytha filiformis & Batang & TBC \\
\hline & Dracaena angustifolia & Daun & \\
\hline
\end{tabular}


Pembuatan media middlebrook broth.

Sebanyak $2.35 \mathrm{~g}$ middlebrook $7 \mathrm{H} 9$ broth base media dimasukkan kedalam $450 \mathrm{ml}$ aquades ditambah $1 \mathrm{ml}$ gliserol. Setelah semua terlarut, sterilkan dengan autoklaf pada $121^{\circ} \mathrm{C}$ selama 20 menit. Masukkan 1 vial OADC ketika akan digunakan, campurkan dengan dengan sempurna.

\section{Penyiapan larutan ekstrak dan infus uji.}

Ekstrak kering ditimbang masing-masing sebanyak $300 \mathrm{mg}$, tambahkan $3 \mathrm{ml}$ aquades, vortex sampai larut dan homogen. Ambil larutan ekstrak dengan spuit, saring dengan filter steril ukuran $0,2 \mu \mathrm{m}$, tampung filtrat dalam tabung tutup ulir steril. Beberapa sampel langsung menggunakan infus yang baru dibuat, tanpa dikeringkan terlebih dahulu.

\section{Pembuatan suspensi bakteri.}

Pembuatan suspensi bakteri dilakukan dengan cara seperti pada butir a, namun menggunakan bakteri hasil peremajaan. Untuk membuat suspensi bakteri $10^{6}$ $\mathrm{cfu} / \mathrm{ml}$, dengan menyiapkan media middlebrook $7 \mathrm{H} 9$ broth sebanyak 3 tabung, masing-masing berisi $30 \mathrm{ml}$, ambil $300 \mu$ l buang. Ambil $300 \mu$ l suspensi bakteri $10^{8}$ $\mathrm{cfu} / \mathrm{ml}$ masukkan dalam media, bolak balik sampai homogen.

\section{Inokulasi pada media middlebrook broth.}

Siapkan $1 \mathrm{ml}$ ekstrak uji dengan konsentrasi 100 $\mathrm{mg} / \mathrm{mL}$ dan aquadest untuk kontrol (+), kontrol (-), obat standar. Masukkan $1 \mathrm{ml}$ suspensi bakteri $10^{6} \mathrm{cfu} / \mathrm{ml}$, inkubasi pada $37^{\circ} \mathrm{C}$ selama 2 minggu. Semua sampel, kontrol dan obat standar dibuat dengan $3 x$ pengulangan.

\section{Pembuatan media LJ modified $\mathrm{pH} 6.8$.}

Campurkan $1.2 \mathrm{~g}$ monokalium fosfat, $0.12 \mathrm{~g}$ magnesium sulfat heptahidrat, 0,3 g magnesium sitrat, $1.8 \mathrm{~g}$ L-asparagine dan $6 \mathrm{ml}$ gliserol kemudian larutkan dengan $300 \mathrm{ml}$ aquadest, campur hingga homogen (larutan a). Siapkan $10 \mathrm{ml}$ malachite green $2 \%$. Selanjutnya kedua larutan tersebut disterilkan dengan autoklaf pada $121^{\circ} \mathrm{C}$ selama 20 menit, kemudian dinginkan. Telur itik kampung yang masih baru dan kondisinya baik (maksimal 1 minggu setelah ditelurkan) dicuci bersih dengan sabun dan disikat, selanjutnya rendam dalam alkohol 70\% selama 15 menit. Sebanyak 12 butir telur yang dipecahkan satu persatu kemudian blender dengan kecepatan rendah sampai merata.
Saring telur dengan kain kasa steril dan ukur sebanyak $500 \mathrm{ml}$. Tuangkan malachite green ke dalam larutan a, kemudian telur juga dimasukkan, homogenkan dengan stirer magnetik. Media yang sudah homogen dituangkan ke botol $\mathrm{mc}$ Cartney sebanyak $\pm 8 \mathrm{ml}$ kemudian dimiringkan diatas nampan, selanjutnya masukkan ke dalam oven blower $85^{\circ} \mathrm{C}$ selama 45 menit sampai mengeras. Keluarkan media pada suhu ruangan dan amati selama 2 hari terhadap adanya kontaminasi.

\section{Inokulasi pada media LJ modified agar.}

Masing-masing sampel pengulangan pada tahap e) dibuat dalam 2 botol media $\mathrm{L}$. Ambil sebanyak $100 \mu \mathrm{l}$ suspensi pada tahap e), tuangkan pada permukaan media $\amalg$ modified, kemudian ratakan hingga keseluruh permukaan. Selanjutnya inkubasikan miring pada $37^{\circ} \mathrm{C}$ selama 48 jam, dilanjutkan pada posisi botol tegak sampai 3 minggu.

Pengamatan pertumbuhan M. tuberculosis pada media LJ modified Agar.

Pengamatan dilakukan pada setiap minggunya selama 3 minggu, catat hasil pengamatan. Media yang ditumbuhi $M$. tuberculosis berarti resisten, sedangkan media yang tidak ditumbuhi berarti sensitif terhadap M. tuberculosis. Media yang kontaminasi langsung dipisahkan unutuk menghindari kontaminasi pada tabung yang lain. Media yang ditumbuhi $M$. tuberculosis selanjutnya dibuat slide dan diwarnai dengan pewarnaan Ziehl Neelsen.

\section{HASIL DAN PEMBAHASAN}

Skrining aktivitas anti tuberkulosis dilakukan pada sampel tanaman baik berupa tanaman tunggal maupun ramuan dari beberapa tanaman hasil dari kegiatan eksplorasi Ristoja 2012. Skrining menggunakan bakteri M. tuberculosis H37Rv umur 4 minggu dan konsentrasi ekstrak $100 \mathrm{mg} / \mathrm{ml}$. Media yang digunakan pada penelitian ini adalah Middlebrook 7H9 broth dengan OADC enrichment dan LJ modified agar. Ekstrak dikontakkan terlebih dahulu pada MTB dalam media Middlebrook 7H9 broth dengan OADC enrichment konsentrasi $10^{6} \mathrm{cfu} / \mathrm{ml}$ selama 2 minggu kemudian dipindahkan pada media $L$ modified agar selama 3 minggu. Ekstrak yang resisten (MTB tumbuh) selanjutnya dibuat slide dan diwarnai dengan pewarnaan Ziehl Neelsen dan diamati pada perbesaran 100x untuk memastikan bakteri tahan asam (BTA). Sedangkan ekstrak yang sensitif selanjutnya dilanjutkan

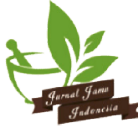


dengan uji untuk menentukan MIC (Minimum Inhibitory Concentration).

Skrining dilakukan pada 26 ekstrak bagian tanaman tunggal dan 16 ekstrak ramuan. Dari total 42 ekstrak sebanyak 15 ekstrak dapat menghambat pertumbuhan bakteri Mycobacterium tuberculosis H37Rv 100\% (sensitif), sisanya tidak menghambat pertumbuhan bakteri (resisten). Sebanyak 9 ekstrak tanaman tunggal dapat menghambat pertumbuhan bakteri Mycobacterium tuberculosis H37Rv 100\% pada konsentrasi $50 \mathrm{mg} / \mathrm{ml}$, yaitu Blumea balsamifera (daun), Clausena excavata (daun), Pluchea indica (daun), Plecthrantus scuttelaroides (daun), Cocos nucifera (daun), Piper betle (daun), Loranthus sp. (herba), Phyllanthus reticulatus (kulit batang), dan Nicotiana tabaccum (daun); sebanyak 2 ekstrak tanaman tunggal pada konsentrasi $25 \mathrm{mg} / \mathrm{ml}$ yaitu Angiopteris evecta (rimpang) dan Arenga pinnata (kapas batang dalam warna kehitaman); serta 1 infusa tanaman tunggal pada konsentrasi $50 \%$ yaitu Caesalpinia sappan L. (batang). Data hasil ditampilkan dalam Tabel 3.

Tabel 3. Skrining Aktivitas Anti Tuberkulosis Ekstrak Tanaman Tunggal

\begin{tabular}{|c|c|c|}
\hline Tanaman & Bagian Yang Digunakan & Aktivitas Anti-TB \\
\hline \multicolumn{3}{|c|}{ Ekstrak Air Konsentrasi 50 mg/ ml } \\
\hline Areca catechu & Akar & Resisten \\
\hline Blumea balsamifera & Daun & Sensitif \\
\hline Clausena excavata & Daun & Sensitif \\
\hline Pluchea indica & Daun & Sensitif \\
\hline Cordyline fruticosa & Daun & Resisten \\
\hline Plecthrantus scuttelaroides & Daun & Sensitif \\
\hline Cocos nucifera & Daun & Sensitif \\
\hline Piper betle & Daun & Sensitif \\
\hline Loranthus sp. & Herba & Sensitif \\
\hline Phyllanthus reticulatus & Kulit batang & Sensitif \\
\hline Nicotiana tabaccum & Daun & Sensitif \\
\hline Plecthrantus amboinicus & Daun & Resisten \\
\hline \multicolumn{3}{|c|}{ Ekstrak Air Konsentrasi 25 Mg/ Ml } \\
\hline Angiopteris Evecta & Rimpang & Sensitif \\
\hline Leersea hexandra & Daun & Resisten \\
\hline Ceiba pentandra & Batang & Resisten \\
\hline Arenga pinnata & Kapas batang muda & Resisten \\
\hline Arenga pinnata & Kapas batang muda (kehitaman) & Sensitif \\
\hline Musa $\times$ paradisiaca & Tunas & Resisten \\
\hline Musa $x$ paradisiaca & Buah & Resisten \\
\hline Euphorbia pulcherrima & Daun & Resisten \\
\hline \multicolumn{3}{|l|}{ Infusa konsentrasi 5\% } \\
\hline Caesalpinia sappan L. & Batang & Sensitif \\
\hline Jatropha curcas & Kulit batang & Resisten \\
\hline Curcuma domestica & Rimpang & Resisten \\
\hline Saccharum officinarum & Umbut & Resisten \\
\hline Averrhoa carambola & Kulit buah & Resisten \\
\hline Eleutherina americana & Umbi & Resisten \\
\hline *Streptomisin & & Sensitif \\
\hline *Isonoazid & & Sensitif \\
\hline *Rifampisin & & Sensitif \\
\hline *Etambutol & & Sensitif \\
\hline
\end{tabular}


Tabel 4. Skrining Aktivitas Anti Tuberkulosis Ekstrak Ramuan

\begin{tabular}{|c|c|c|}
\hline Komposisi Ramuan & Bagian Yang Digunakan & Aktivitas Anti-TB \\
\hline \multicolumn{3}{|l|}{ Ekstrak Air Konsentrasi 25 mg/ml } \\
\hline Leersea hexandra & Daun & \\
\hline Ceiba pentandra & Daun & Resisten \\
\hline Pistia stratiotes & Herba & \\
\hline Gynura procumbens & Daun & Resisten \\
\hline Allium sativum & Umbi & \\
\hline Coix lacryma-jobi & Akar & \\
\hline Saccharum officinarum & Akar & \\
\hline Musa x paradisiaca & Akar & Resisten \\
\hline Carica papaya & Akar & \\
\hline Morinda citrifolia & Akar & \\
\hline Oryza sativa & Beras & \\
\hline Curcuma domestica & Rimpang & Resisten \\
\hline Ketumbar & Biji & \\
\hline Jatropha curcas & Akar & Sensitif \\
\hline Citrus aurantifolia & Air jeruk & \\
\hline Artemisia vulgaris & Daun & Resisten \\
\hline Curcuma xanthorrhiza & Rimpang & \\
\hline Vitex trifolia & Pucuk daun & \\
\hline Loranthus sp & Herba & Sensitif \\
\hline Orthosiphon aristatus & Pucuk daun & \\
\hline Blumea lacera & Akar & Resisten \\
\hline Cocos nucifera & Air Kelapa muda & \\
\hline Cassytha filiformis & Batang & Resisten \\
\hline Dracaena angustifolia & Daun & \\
\hline \multicolumn{3}{|l|}{ Infusa 5\% } \\
\hline Blumea balsamifera & Daun & Resisten \\
\hline Clausena excavate & Daun & \\
\hline Artocarpus heterophyllus Lamk & Buah & \\
\hline Sesbania grandiflora & Kulit batang & Resisten \\
\hline Lannea coromandelica & Kulit batang & \\
\hline Tamarindus indica & Buah & Sensitif \\
\hline Curcuma heyneana & Rimpang & \\
\hline Aleurites moluccana & Daun tua & Resisten \\
\hline Cocos nucifera & Sabut & \\
\hline Curcuma domestica & Rimpang & Resisten \\
\hline Plumeria rubra & Kulit batang & \\
\hline Blumea lacera & Akar & Resisten \\
\hline Cocos nucifera & Air Kelapa muda & \\
\hline Cymbopogon nardus & Akar & \\
\hline Areca catechu & Daging buah & Resisten \\
\hline Jatropha curcas & Kulit batang & \\
\hline
\end{tabular}


Uji aktivitas antituberkulosis dengan ekstrak ramuan didapatkan sebanyak 3 ekstrak ramuan efektif menghambat pertumbuhan bakteri Mycobacterium tuberculosis H37Rv sebanyak 100\%. Ekstrak ramuan Tamarindus indica L. (buah), dengan Curcuma heyneana (rimpang) dosis $25 \mathrm{mg} / \mathrm{ml}$ dan infusa $50 \%$ ramuan Jatropha curcas L. (akar), dengan Citrus aurantifolia (air buah), Vitex trifolia (daun) dengan Loranthus sp. (herba) dengan Orthosiphon aristatus (daun) memiliki aktivitas antituberkulosis. Data Hasil ditampilkan dalam Tabel 4.

Penggunaan ramuan (jamu) menggunakan tanaman obat pada pengobatan tuberkulosis diharapkan mampu menjadi pengobatan komplementer dengan adanya resistensi terhadap antibiotik tertentu pada pengobatan konvensional (obat kimia). Beberapa suku di Indonesia ternyata memiliki kearifan lokal yang cukup menarik untuk dikembangkan salah satunya pengobatan tuberkulosis menggunakan tanaman obat (jamu). Namun demikian masih sedikit data maupun penelitian yang telah mengangkat atau memberikan pembuktian secara ilmiah terhadap jamu-jamu yang oleh warga lokal maupun hattra telah diklaim memiliki aktivitas untuk penyakit tersebut.

Aktivitas anti tuberkulosis pada jamu mungkin merupakan kerja dari salah satu atau beberapa kandungan kimia yang terdapat pada tanaman obat antara lain hasil penelitian pada tannin yang diisolasi dari Combretum molle (Asres, 2001), alkaloid dari Alstonia Scholaris (Macabeo, 2005) Justicia adhatoda (Kumar Jha et al. 2012), triterpenoid saponin Sapium haematospermum (Woldemichael, 2004), Flavonoid dari Dorstenia barteri, Lorrea tiridentale, asam sinamat (Askun, 2015) memiliki aktivitas anti Mycobacterium tuberculosis. Flavonoid butein dan isoliquiritigenin memiliki aktivitas menghambat biosintesis asam lemak dan asam mikolat (Askun, 2015).

Beberapa strain Blumea balsamifera, YIM 56092, YIM 56093 dilaporkan memiliki aktivitas anti-mikrobial terhadap S. epidermidis;YIM 56099 terhadap E. coli. Minyak atsiri Blumea balsamifera menghambat pertumbuhan Bacillus cereus, ekstrak heksan sktif terhadap Enterobacter cloacae dan S. aureus (Pang et al. 2014). Data tersebut menunjukkan bahwa Blumea balsamifera memiliki aktivitas anti-mikrobial terhadap bebebrapa bakteri termasuk M. tuberculosis.

Ekstrak metanol Caesalpinia sappan dikatakan lebih efektif sebagai antimikroba dibandingkan ekstrak air (Mohan et al. 2011; Chandra 2013) Namun bukan berarti bahwa ekstrak air secang tidak memiliki aktivitas antimikroba. Ekstrak air secang dapat menghambat pertumbuhan Staph. aureus, B. subtilis, E. coli, $P$. aeruginosa, Proteus vulgaris dengan MIC 0,22$0,86 \mathrm{mg} / \mathrm{ml}$ (Mohan et al. 2011), Salmonella typhi, Strep. Facealis, Enterobacter aerogens, C. albicans, Aspergillus niger (Srinivasan et al. 2012). Secang memiliki komponen kimia diantaranya tannin dan alkaloid, tannin dan alkaloid telah dilaporkan merupakan komponen yang memiliki aktivitas antimikroba. Tannin mampu menyebabkan disintegrasi koloni dan merusak dinding sel sehingga menyebabkan pertumbuhan mikroba terhambat (Mohan et al. 2011).

Kelapa (Cocos nucifera) telah digunakan secara luas seluruh bagian tanamannya baik untuk kerajinan, makanan, maupun untuk pengobatan. Monogliserida buah kelapa efektif menghambat bakteri E. coli, $P$. aeruginosa, S. aureus, C. albicans. (DebMandal dan Mandal, 2011).

\section{SIMPULAN}

Dari penelitian diatas disimpulkan bahwa dari 26 ekstrak tanaman tunggal yang diujikan pada bakteri Mycobacterium tuberculosis H37Rv dapat menghambat pertumbuhan bakteri tersebut $100 \%$ pada dosis 50 $\mathrm{mg} / \mathrm{ml}$ sebanyak 9 ekstrak tunggal yaitu Blumea balsamifera (daun), Clausena excavata (daun), Pluchea indica (daun), Plecthrantus scuttelaroides (daun), Cocos nucifera (daun), Piper betle (daun), Loranthus sp. (herba), Phyllanthus reticulatus (kulit batang), dan Nicotiana tabaccum (daun); pada dosis $25 \mathrm{mg} / \mathrm{ml}$ sebanyak 2 ekstrak tunggal yaitu Angiopteris evecta (rimpang) dan Arenga pinnata (kapas batang dalam warna kehitaman); serta 1 infusa tanaman tunggal yaitu Caesalpinia sappan L. (batang).

Ekstrak ramuan Tamarindus indica L. (buah), dengan Curcuma heyneana (rimpang) dosis $25 \mathrm{mg} / \mathrm{ml}$ dan infusa ramuan Jatropha curcas L. (akar), dengan Citrus aurantifolia (air buah), Vitex trifolia (daun) dengan Loranthus sp. (herba) dengan Orthosiphon aristatus (daun) dapat menghambat pertumbuhan bakteri Mycobacterium tuberculosis H37Rv sebanyak $100 \%$.

\section{UCAPAN TERIMAKASIH}

Penulis mengucapkan terima kasih kepada Kepala Balai Besar Penelitian dan Pengembangan Obat Tradisional, PPI, segenap koordinator teknis Ristoja, Kepala Laboratorium Tuberkulosis Bagian Mikrobiologi Fakultas Kedokteran UGM dan tim, serta seluruh tim

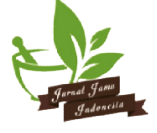


penelitian skrining antituberkulosis atas segala bantuan yang diberikan.

\section{DAFTAR PUSTAKA}

Askun T. 2015. The Significance of Flavonoids as a Potential Anti-Tuberculosis Compounds. Research \& Reviews: Journal of Pharmacology an Toxicological Studies Vol 3 Issue 3

Asres K, Bucar F, Edelsbrunner S, Kartnig T, Hoger G, Thiel W. 2001. Investigations of Antimycobacterial Activity of Some Ethiopian Medicinal Plants. Phytotherapy Research. 15:323-326.

Bongo G, Tuntufye H, Ngbolua K Malakalingna J, Claudine T, Pambu A, Mwanza F, Mbadiko C, Makengo G, Iteku J, Tshilanda D, Mpiana P, Mbemba T, Kazwala R. 2017. Comparative Antimycobacterial Activity on Lowenstein-Jensen Slants of Selected Medicinal Plants Used in the Congolese Pharmacopeia. Journal of Diseases and Medicinal Plants. 3(5):88-96.

Chandra HJ. 2013. Screening of Antimicrobial Activity and Phytochemical Analysis of Caesalpinia sappan L. Journal of Chemical and Pharmaceutical Research. 2013,5(3):171-175.

Christanto A. 2018. Paradigma Baru Tuberkulosis pada Era Sustainable Development Goals (SDGs) dan Implementasinya di Indonesia. Cermin Dunia Kimia. 45(1):57-60.

DebMandal M, Mandal S. 2011. Coconut (Cocos nucifera L.: Arecaceae): In Health Promotion and Disease Prevention. Asian Psific Journal of Tropical Medicine. 4(3): 241-247

Kemenkes RI. 2015. Survei Prevalensi Tuberkulosis Indonesia 2013-2014. Jakarta (ID): Badan Penelitian dan Pengembangan Kesehatan, Direktorat Jenderal Pengendalian Penyakit dan Penyehatan Lingkungan.

Macabeo APG, Krohn K, Gehle D, Read RW, Brophy JJ, Cordell GA, Franzblau SG, Aguinaldo AM. 2005. Indole alkaloids from the leaves of Philippine Alstonia scholaris. Phytochemistry. 66(10):11581162.
Mohan G, Anand SP. 2011. Efficacy of Aqueous and Methanol extracts of Caesalpinia sappan L. and Mimosa pudica L. for Their Potential Antimicrobial Activity. South As. Journal of Biological Sciences. 1 (2):48-57.

Pang Y, Wang D, Fan Z, Chen X, Yu F, Hu X, Wang K, Yuan L. 2014. Blumea balsamifera - A Phytochemical and Pharmacological Review. Molecules. 19:94539477; doi:10.3390/molecules19079453.

Srinivasan R, Ganapathy SG; Karthik S, Mathivanan K, Baskaran R, Karthikeyan M, Gopi M. 2012. In Vitro Antimicrobial Activity of Caesalpinia sappan L. Asian Pasific Journal of Tropical Biomedicine. S136-S139.

Wahyono S, Jokopriyambodo W, Mustofa FI, Rahmawati N, Sari AN, Maruzy A, Mujahid R, Widowati L, Widyastuti $Y$, Subositi D, Budiarti M, Haryanti S, Junediyono. 2017. Laporan Nasional Eksporasi Pengetahuan Lokal Etnomeisin dan Tumbuhan Obat Berbasis Komunitas di Indonesia. Jakarta (ID): Lembaga Penerbitan Badan Litbangkes.

Wahyuningrum, R; Ritmaleni; Irianti, T, Wahyuono, S; Kaneko, T. Antituberculosis Activity of Extract and Fractions of Tinosprora crispa against Mycobacterium tuberculosis H37RV Using Mycobacterian Growth Indicator Tube and Agar Proportion Method. Asian Journal of Pharmaceutical and Clinical Research. 11(3):132-135 WHO. 2015. The End TB Strategy. http://www.who.int/tb/End_TB_brochure pdf

WHO a. 2017. Global Tuberculosis Report 2017. http://who.int/tb/publications/globalreport/gtbr2017_main_text.pdf

Woldemichael GM, Gutierrez-Lugo MT, Franzblau SG, Wang Y, Suarez E, Timmermann BN. 2004. Mycobacterium tuberculosis Growth Inhibition by Constituents of Sapium haematospermum. Journal of Natural Products. 67 (4):598-603. 